\title{
Tooth Decay Prevention: Knowledge and Practices Survey of Dental Students
}

\author{
Fuad A Al-Sabri ${ }^{1}$, Mohammed Ba-Salamah², Ahmed M El-Marakby ${ }^{3}$, Sherif Okash ${ }^{4}$, Ibrahim H Ghaleb ${ }^{5}$, Saleem Abdulrab ${ }^{6}$
}

\begin{abstract}
Objectives: This study aimed to assess the level of knowledge, attitudes, and practices fissure sealants among undergraduate Saudi dental students.

Methods: A modified questionnaire consisted of 24-items was distributed among 226 undergraduate dental students, males and females of different years at Al-Farabi Colleges, Riyadh, Saudi Arabia. Chi-square/Fisher's exact tests were used for descriptive statistical analyses.

Results: The response rate was $100 \%$. Most of the respondents were male (60.2) and (39.8\%) were female. With regard to the level of study, $20.8 \%$ were in the fourth year, $43.8 \%$ in the fifth year, and $16.8 \%$ were in the sixth year. The respondents showed a sensible level of learning about sealants, with the majority (88\%) believed that there is strong scientific evidence about fissure sealants effectiveness and around $90 \%$ showed a good understanding of sealant placement instructions. Furthermore, respondents demonstrated inadequate learning about sealants clinical practice. Conclusion: Despite a high proportion of undergraduate dental students'showed sufficient knowledge about dental sealant, following guidelines and standardized procedures in clinical practice is lacking. The findings suggest an urgent need of dental colleges to additionally and/or update their curriculum regarding fissure sealants to reflect advance dental education that concentrates on evidence-based practice (EBP) in Pediatric Dentistry and Dental Public Health need for regular continuing education courses for the dental professional.

Keywords: Dental students, Fissure sealants, Knowledge, Prevention.

International Journal of Clinical Pediatric Dentistry (2019): 10.5005/jp-journals-10005-1599
\end{abstract}

\section{INTRODUCTION}

Dental caries prevention in children and adolescents involves a range of population and individual level strategies that may include dental sealants. Dental sealant programs typically target students in the second grade, when the first permanent molars have generally erupted, and, in the sixth grade, when the second permanent molars have generally erupted. ${ }^{1}$ Dental sealants are applied as a preventive measure to cover pit and fissures on the occlusal surfaces of children or teeth at risk for developing caries. Since 2000, the prevalence of dental sealants among 8 years old children and 14 years old adolescents has increased. ${ }^{2}$

By the age of 15, the dietary habits of the individuals are more or less established and the permanent teeth have been exposed to the oral environment for 3-9 years, thus, making the evaluation of caries prevalence even more meaningful at this age. ${ }^{2}$ The age of 12 years has been universally accepted as a global monitoring age for caries because all permanent teeth except third molars would most likely have erupted by this age.

Pit and fissure caries account for approximately $80-90 \%$ of all caries in permanent posterior teeth and $44 \%$ in primary teeth. ${ }^{3}$ The pit and fissure sealant has been described as a material placed into the pits and fissures of caries susceptible teeth that micromechanically bonds to the tooth preventing access by cariogenic bacteria to their source of nutrients, thus, reducing the risk of caries in those susceptible pits and fissures. ${ }^{4}$

Dental caries is the most common form of infection that can be prevented during the stage of childhood, and the techniques are currently available to cost effectively reduce caries. ${ }^{5,6}$ The most efficient method to decrease occlusal caries are pit and fissure sealants, and, over the most recent 4 years, more than 11 guidelines and systematic reviews have suggested the pit and fissure sealant
${ }^{1}$ Department of Operative Dentistry, Faculty of Dentistry, Thamar University, Thamar, Yemen

${ }^{2,4}$ Department of Preventive Dental Sciences, AL-Farabi Colleges, Riyadh, Saudi Arabia

${ }^{3}$ Department of Operative Dentistry, Al-Azhar University, Assiut, Egypt

${ }^{5}$ Department of Restorative Dental Sciences, AL-Farabi Colleges, Riyadh, Saudi Arabia

${ }^{6}$ Primary Health Care Corporation, Doha, Qatar

Corresponding Author: Fuad A Al-Sabri, Department of Operative Dentistry, Faculty of Dentistry, Thamar University, Thamar, Yemen, Phone: +967 771805807, e-mail: alsabrifuad@yahoo.com

How to cite this article: Al-Sabri FA, Ba-Salamah M, et al. Tooth Decay Prevention: Knowledge and Practices Survey of Dental Students. Int J Clin Pediatr Dent 2019;12(2):92-95.

Source of support: Nil

Conflict of interest: None

use for at-risk populations. ${ }^{3,7-16}$ The caries prevalence is related to the form and depth of pits and fissures. ${ }^{17}$

Sealants are efficient in decreasing occlusal caries incidence in permanent first molars of children, with caries decreases of $76.3 \%$ at 4 years, when sealants were reapplied as needed. Caries reduction was $65 \%$ at 9 years from initial treatment, with no reapplication during the last 5 years. ${ }^{18}$ Dental sealants were introduced in the 1960 s to help prevent dental caries in the pits and fissures of mainly the occlusal tooth surfaces. ${ }^{19}$ This study aimed to assess the level of knowledge, attitudes, and practices fissure sealants among undergraduate Saudi dental students.

() The Author(s). 2019 Open Access This article is distributed under the terms of the Creative Commons Attribution 4.0 International License (https://creativecommons. org/licenses/by-nc/4.0/), which permits unrestricted use, distribution, and non-commercial reproduction in any medium, provided you give appropriate credit to the original author(s) and the source, provide a link to the Creative Commons license, and indicate if changes were made. The Creative Commons Public Domain Dedication waiver (http://creativecommons.org/publicdomain/zero/1.0/) applies to the data made available in this article, unless otherwise stated. 


\section{Materials and Methods}

A cross-sectional survey was conducted using a self-administered questionnaire involving different levels in the undergraduate dental students' male and female at Al-Farabi Colleges, Riyadh, Saudi Arabia. These questionnaires were sent to 226 undergraduate dental students, selected randomly from Al-Farabi Colleges, Riyadh, Saudi Arabia. The study was conducted in a full agreement with the declared ethical principles of the World Medical Association Declaration of Helsinki (2002). The study was administered during June 2016. The self-administered survey was adapted from pretested questionnaires that have been applied in similar studies. ${ }^{2,12}$ Before distributing the survey, a pilot study was performed on a random sample of undergraduate dental students $(n=20)$, and the survey was modified according to the feedback obtained. The first section of the questionnaire sought demographic data of the participants including age, gender, qualification, and year of undergraduation. The second section included questions that focused on dental students' knowledge and practices regarding fissure sealants. Chi-square tests were used $(p<0.05)$. The data were analyzed using IBM SPSS software (version 16; IBM, Armonk, NY, USA).

\section{Results}

A total of 226 questionnaires were distributed and collected, giving a response range of $100 \%$. Of these, $136(60.2 \%)$ were males and 90 (39.8\%) were female. With regard to the level of study, $20.8 \%$ were in the fourth year, $43.8 \%$ in the fifth year, and $16.8 \%$ were in the sixth year (Table 1).

Most of the respondents thought that the effectiveness of dental sealant is supported by a strong scientific evidence (91.4\%). On the one hand, $83.4 \%$ were familiar with the technique of placing dental sealant and $90.6 \%$ ensured that they understand the instructions for placing sealants, with no statistical significant differences between male and female students. On the other hand, there was a statistical difference between male and female students when they were asked whether sealant should only be used on newly erupted teeth, as $74.2 \%$ of male students compared to only $36.7 \%$ of females agreed with that opinion $(p=0.000)$. Nearly similar results were reported about the expected adverse effects that might occur after using the pit and fissure sealant (58.3\% male, 31\% female and $p=0.000$ ). Around $57.8 \%$ of the respondents concurred with that resin sealants are more effective than the glass ionomer sealant with a statistical significant difference between males and females ( $p=0.009)$.

No statistically significant differences were reported between male and female respondents with regard to the other items. The vast majority $(79.2 \%)$ of the respondents agreed with that the most important aspect to the success of the treatment is the technique of

Table 1: Demographic data of the subjects $(n=226)$

\begin{tabular}{ll}
\hline Variables & $n(\%)$ \\
\hline Gender & \\
Male & $136(60.2)$ \\
Female & $90(39.8)$ \\
Year of undergraduate & \\
4th year & $(20.8)$ \\
5th year & $(43.8)$ \\
6th year & $(16.8)$ \\
\hline
\end{tabular}

application, and $75.7 \%$ of the respondents recommended to apply proper acid etching to get high adhesion between teeth and fissure sealant materials. About $75.1 \%$ of the respondents thought that a sealant is a preventive method, as well have a restorative effect and can be used on incipient caries and about $84.3 \%$ of the respondents believed that the sealing technique, when used beside fluoride application, may decrease the rate of caries more significantly. This is collected in Table 2.

With regard to fissure sealants practices, only $37.5 \%$ of students reported that they always avoid the dental sealant for the possibility of sealing over caries. More than half of the respondents (56.3\%) recommended reapplication of sealant in case of a partial or total sealant loss. Around $68.8 \%$ of the respondents reported that they always clean the tooth surface before placement of the fissure sealant, and $70.9 \%$ of the respondents follow the instructions from the manufacturer (Table 3).

\section{Discussion}

This study evaluated the knowledge, attitudes, and practice of fissure sealants among undergraduate dental students' at Al-Farabi Colleges, Riyadh. We believe, this is the first report to explore such topic among dental students in Saudi Arabia; in this study, the undergraduate dental students revealed a fairly acceptable level of knowledge about fissure sealants. However, their responses to practice questions were rather insufficient, indicating to some degree lack of the present clinical awareness of sealants usage.

The most amazing result of the study was that around $8.4 \%$ of the undergraduate dental students reported that they suffered from lack of information about the fissure sealant, indicating that a considerable percentage of the students are unaware of fissure sealant importance in the dental field. Such alarming result can be attributed to inadequate university education or lack of stressing at these important subjects during the study plan of the dental program. Dental colleges need to contain and/or update their syllabus concerning fissure sealants to reflect recent dental education that concentrates on evidence-based practice (EBP) in Pediatric Dentistry and Dental Public Health. In this era of modern dentistry, it is important to integrate the principles of evidence-based dental practice to the dental curriculum. ${ }^{16-18}$ In the present study, around $8 \%$ of students were concerned about insufficient evidence of fissure sealant effectiveness, a finding that underscores the importance of teaching EBP to dental students' education courses. ${ }^{13}$ Most of the students in the present study supposed that there is some scientific evidence of fissure sealants as a preventive measure, and they also showed a well understanding of the instructions of sealant placement and exhibited familiarity with the fissure sealant placement technique. These findings are an agreement with previous reports. ${ }^{2,12-14}$

Over two-thirds of the students (77.7\%) favored using a sealant beside with fluoride and strongly supposed in their synergistic effects to reduce dental caries, a similar result was also observed by Al-Maweri et al. ${ }^{20}$. Research has shown that using fluoride prior to sealant application may increase caries protection, without compromising on the properties of the sealant. Additionally, the addition of fluoride to a sealant has been reported to be cariostatic to the enamel area. ${ }^{4,19}$ In this study, we observed some significant differences between males and females where male students showed better knowledge and attitudes compared with their females counterparts. ${ }^{13}$ A disappointing finding in the 
Table 2: Knowledge, opinions and attitudes regarding fissure sealant by gender

\begin{tabular}{|c|c|c|c|c|}
\hline \multirow[b]{2}{*}{ Questions } & \multicolumn{2}{|c|}{ Gender } & \multirow[b]{2}{*}{ Total (\%) } & \multirow[b]{2}{*}{ pvalue } \\
\hline & Male (\%) & Female (\%) & & \\
\hline $\begin{array}{l}\text { I think that the effectiveness of dental sealant is supported by a strong } \\
\text { scientific evidence. }\end{array}$ & 92.5 & 89.9 & 91.4 & NS \\
\hline I am familiar with the technique of placing dental sealant. & 82.1 & 85.4 & 83.4 & NS \\
\hline I understand the instructions for placing sealants. & 92.5 & 87.6 & 90.6 & NS \\
\hline The sealant should only be used on newly erupted teeth. & 74.2 & 36.7 & 59 & 0.000 \\
\hline The sealants wear out easily. & 67.7 & 52.9 & 61.8 & NS \\
\hline Pit and fissure sealant have an adverse effect. & 58.3 & 31 & 47.2 & 0.000 \\
\hline $\begin{array}{l}\text { The technique of application is the most important aspect of the success of } \\
\text { the treatment. }\end{array}$ & 76.5 & 83.1 & 79.2 & NS \\
\hline Resin sealants are more effective than glass ionomer sealant. & 65.9 & 45.5 & 57.8 & 0.009 \\
\hline Apply proper acid etching to get high adhesion is recommended. & 77.1 & 73.6 & 75.7 & NS \\
\hline $\begin{array}{l}\text { I think the sealant is a preventive method, as well have a restorative effect } \\
\text { and can be used on incipient caries. }\end{array}$ & 71.1 & 81.1 & 75.1 & NS \\
\hline $\begin{array}{l}\text { This sealing technique, when used alongside fluoride application, may } \\
\text { reduce the rate of decay more significantly. }\end{array}$ & 73.3 & 84.3 & 77.7 & NS \\
\hline
\end{tabular}

Table 3: Questions regarding fissure sealants practices

\begin{tabular}{|c|c|c|c|c|}
\hline Questions & Always (\%) & Sometimes (\%) & Rarely (\%) & Never (\%) \\
\hline I sometimes avoid dental sealant for the possibility of sealing over caries. & 37.5 & 35.3 & 12.1 & 15.2 \\
\hline In case of a partial or total loss of sealant, I would recommend reapplication. & 56.3 & 39.2 & 2.7 & 1.8 \\
\hline $\begin{array}{l}\text { The most important factor for adhesion to occur in sealant placement is proper } \\
\text { isolation. }\end{array}$ & 69.3 & 28.4 & 1.8 & 0.4 \\
\hline $\begin{array}{l}\text { The most important factor for adhesion to occur in sealant placement is proper acid } \\
\text { etching. }\end{array}$ & 67.3 & 30.9 & 1.3 & 0.4 \\
\hline The benefit of using sealant should be considered with regard to the patient's risk. & 65.0 & 27.8 & 5.4 & 1.8 \\
\hline I clean the tooth surface before placement of fissure sealant. & 68.8 & 25.8 & 3.6 & 1.8 \\
\hline $\begin{array}{l}\text { I follow the manufacture instructions for placing light cure on the tooth while } \\
\text { putting sealant materials. }\end{array}$ & 70.9 & 26.5 & 1.8 & 0.9 \\
\hline I apply bonding agent after acid etching on the occlusal surface. & 56.4 & 28.4 & 4.1 & 11.0 \\
\hline I use a rubber dam in the time of placing fissure sealant. & 50.7 & 40.6 & 6.8 & 1.8 \\
\hline $\begin{array}{l}\text { I use conventional way such as cotton roles to isolate adjacent soft tissue while } \\
\text { placing sealant. }\end{array}$ & 43.6 & 44.5 & 10.5 & 1.4 \\
\hline $\begin{array}{l}\text { Should I put an extra-amount of sealant in pits and fissure to reach maximum } \\
\text { retention. }\end{array}$ & 67.6 & 27.9 & 3.6 & 0.9 \\
\hline I repeat doing fissure sealant if there is technical mishap has occurred. & 53.6 & 38.3 & 6.8 & 1.4 \\
\hline I apply prophylaxis paste without fluoride before placing sealant. & 49.1 & 34.5 & 9.1 & 7.3 \\
\hline
\end{tabular}

present investigation was that that only $50 \%$ of our students reported using a rubber dam in isolation, a finding which can be attributed to the difficulty in the rubber dam usage. In line with this, a considerable proportion of students reported using cotton rolls. This was in accordance with a previous study among Yemeni dental professionals in which a high preference of cotton rolls over a rubber dam was reported. ${ }^{20}$ It is worth mentioning here that a systematic review conducted by Muller-Bolla et al. ${ }^{3}$ revealed no scientific evidence for the preference of rubber dam over cotton rolls. There is some controversy concerning resealing partially or totally missing sealant. However, some studies reported very small caries practice under sealants, others reported the conflicting. ${ }^{14,21}$

In line with the findings among Spanish and Yemeni dental professionals, a considerable percentage of our students preferred reapplication of sealant in case of a partial or complete loss. ${ }^{12,20}$ On the contrary, another study found that a majority of dental professionals surveyed did not reapply sealants regardless of retention status. ${ }^{2}$ Such inconsistent findings among different studies could be ascribed to a lack of consensus and protocol about the procedure.

It is well established that pits and fissures, mainly of permanent posterior teeth, are vulnerable to caries development and that the morphology of pits and fissures has been reported to be one of the main risk factors. Therefore, dental students and dental practitioners must have profound knowledge about the indications as well as contraindications of fissure sealants application.

\section{Conclusion}

The present study showed that dental students at Al-Farabi Colleges had an acceptable level of knowledge about dental sealants. However, their levels of evidence-based knowledge 
about the appropriate application sealants were unsatisfactory. The findings suggest an urgent need for dental schools to update their curriculum regarding fissure sealants to reflect advance dental education that focuses on EBP. In this era of modern dentistry, it is important to combine the principles of evidence-based dental practice to the dental curriculum for regular continuing education courses to enhance the existing knowledge of fissure sealants among dental practitioners.

\section{References}

1. Tomar SL, Reeves AF. Changes in the oral health of US children and adolescents and dental public health infrastructure since the release of the Healthy People 2010 Objectives. Acad Pediatr 2009;9(6):388395. DOI: 10.1016/j.acap.2009.09.018.

2. Organization WH. Oral health surveys: basic methods. World Health Organization; 2013.

3. Beauchamp J, Caufield PW, et al. Evidence-based clinical recommendations for the use of pit-and-fissure sealants: a report of the American Dental Association Council on Scientific Affairs. J Am Dent Assoc 2008;139:257-268. DOI: 10.14219/jada.archive.2008.0155.

4. Simonsen RJ. Clinical applications of the acid etch technique. IL: Quintessence Publishing, 1978.

5. Benzian $\mathrm{H}$, Hobdell $\mathrm{M}$, et al. Political priority of global oral health: an analysis of reasons for international neglect. Int Dent J 2011;61:124130. DOI: 10.1111/j.1875-595X.2011.00028.x.

6. Pitts N, Amaechi B, et al. Global oral health inequalities: dental caries task group-research agenda. Adv Dent Res 2011;23:211-220. DOI: 10.1177/0022034511402016.

7. Mickenautsch S, Yengopal V. Caries-preventive effect of glass ionomer and resin-based fissure sealants on permanent teeth: an update of systematic review evidence. BMC Res Notes 2011;4:22. DOI: 10.1186/1756-0500-4-22.

8. Hiiri A, Ahovuo-Saloranta A, et al. Pit and fissure sealants vs fluoride varnishes for preventing dental decay in children and adolescents. Cochrane Database Syst Rev 2010; CD003067. DOI: 10.1002/14651858. CD003067.pub3.
9. Yengopal V, Mickenautsch S. Resin-modified glass-ionomer cements vs resin-based materials as fissure sealants: a meta-analysis of clinical trials. Eur Arch Paediatr Dent 2010;11:18-25. DOI: 10.1007/BF03262705.

10. Gooch BF, Griffin SO, et al. Preventing dental caries through schoolbased sealant programs: updated recommendations and reviews of evidence. J Am Dent Assoc 2009;140:1356-1365. DOI: 10.14219/jada. archive.2009.0070.

11. Yengopal V, Mickenautsch S, et al. Caries-preventive effect of glass ionomer and resin-based fissure sealants on permanent teeth: a meta analysis. J Oral Sci 2009;51:373-382. DOI: 10.2334/josnusd.51.373.

12. Marinho VC. Cochrane reviews of randomized trials of fluoride therapies for preventing dental caries. Eur Arch Paediatr Dent 2009;10:183-191. DOI: 10.1007/BF03262681.

13. Griffin SO, Gray SK, et al. Caries risk in formerly sealed teeth. J Am Dent Assoc 2009;140:415-423. DOI: 10.14219/jada.archive.2009.0190.

14. Ahovuo-Saloranta A, Hiiri A, et al. Pit and fissure sealants for preventing dental decay in the permanent teeth of children and adolescents. Cochrane Database Syst Rev 2008; CD001830. DOI: 10.1002/14651858.CD001830.pub5.

15. Azarpazhooh A, Main PA. Pit and fissure sealants in the prevention of dental caries in children and adolescents: a systematic review. J Can Dent Assoc 2008;74:171-177.

16. Griffin SO, Oong E, et al. The effectiveness of sealants in managing caries lesions. J Dent Res 2008;87:169-174. DOI: 10.1177/154405910808700211.

17. Al-Sabri F. Pit and fissure sealant for preventing dental caries in permanent teeth of adolescents. Stomatology 2012;12:11-14.

18. Feigal RJ, Donly KJ. The use of pit and fissure sealants. Pediatr Dent 2006;28:143-150; discussion 92-98.

19. Ahovuo-Saloranta A, Forss $\mathrm{H}$, et al. Sealants for preventing dental decay in the permanent teeth. Cochrane Database Syst Rev 2013; CD001830. DOI: 10.1002/14651858.CD001830.pub4.

20. Al-Maweri SA, Al-Jamaei AA, et al. Fissure sealants: Knowledge and practice of Yemeni dental practitioners. Eur J Dent 2016;10:234-238. DOI: 10.4103/1305-7456.178300.

21. Carvalho JC, Ekstrand KR, et al. Dental plaque and caries on occlusal surfaces of first permanent molars in relation to stage of eruption. J Dent Res 1989;68:773-779. DOI: 10.1177/00220345890680050401. 